\title{
Modified fiber cement panels for civil construction
}

\author{
Rustem Mukhametrakhimov ${ }^{1, *}$ Albert Galautdinov ${ }^{1}$, Liliya Lukmanova $^{1}$, Airat Khuzin $^{1}$, \\ Aleksandr Lamberov ${ }^{2}$ and Svetlana Egorova ${ }^{2}$ \\ ${ }^{1}$ Kazan State University of Architecture and Engineering, Zelenaya str., 1, Kazan, 420043, Russia \\ ${ }^{2}$ Kazan Federal University, Kremlyovskaya str., 18, Kazan, 420008, Russia
}

\begin{abstract}
The authors investigated the influence of modifying agents, based on the realization of three-factor plan of the second-order, on physico-mechanical properties and durability of fiber cement boards based on cellulose fibers.
\end{abstract}

\section{Introduction}

At present, a large proportion of buildings that have long life, do not meet modern thermo-technical and aesthetic requirements. For decoration facades of the newly constructed and renovated buildings with insulation used are ventilated facade systems, which allow to restore the old facades and give them a more modern look. As a facing material in these systems use different materials: granite, aluminum panels, polymeric materials, fiber cement board (FCB), etc. However, most of them are imported from other countries that have high value and can't always be used for building in our weather conditions.

The most widespread and available facing material among the domestic is fiber cement panels are based on the asbestos fibers. However, demand for these products is reduced each year. This is due mainly to disseminate information on the carcinogenicity of asbestos.

In this connection, the question becomes urgent to develop a new effective facing material in an environmentally pure raw materials of low cost, capable of ensuring the reliability, durability and energy efficiency of buildings with the possibility of introducing in the model lines for the production of asbestos-cement boards with the maximum use of existing equipment [1]. One of these materials are FCB on the basis of cellulose fibers. The process of their production is similar to asbestos-cement boards. In fact, asbestos-cement boards are fiber cement, but on the Russian market under a FCB to understand the most common asbestos-free boards.

The disadvantages of the existing FCB based on the cellulosic fibers include low strength, high water absorption [2] and low resistance to frost. In this connection acquire a special urgency work to address issues of quality and durability of the FCB based on the cellulose fibers [3].

*Corresponding author: muhametrahimov@mail.ru 
In our previous investigations carried out $[4,5,6]$ investigated the effect of the matrix (cement: sand) with varying degrees of dispersion of silica sand, the coefficient of fiber reinforcement, the grinding of cellulose fibers on the physico-mechanical characteristics of the FCB. It also investigated the effect of a number of active mineral additives (AMA), characterized by mineralogical composition and hydraulic activity [7], organosilicon compounds and additives of polyacrylamide on the kinetics of hydration mixed binder and physical and mechanical properties of the FCB [8-14].

\section{Experimental section}

This work present the results of experimental researches to improve the hydraulic activity of kaolin and improving physical and mechanical properties and durability of fiber cement boards, based on cellulose fibers produced by the wet method, by combining AMA activated kaolin, organosilicon compound (OSC) - "FES-50 "manufactured by Khimprom (Novocheboksarsk) and polyacrylamide (PCA) «Besfloc K4046» production «KOLON LIFE SCIENCE, INC.» (South Korea).

Hydraulic activity of kaolin increased by firing and subsequent acid activation [15]. Found that the thermal treatment of kaolin increases its hydraulic activity with 693 to 1238 $\mathrm{mg} / \mathrm{g}$, while the optimum temperature of heat treatment of $600{ }^{\circ} \mathrm{C}$, and the processing time 30 min (Fig. 1).

The subsequent activation of metakaolin with $3 \%$ solution formic acid increases the hydraulic activity doubled compared with the original kaolin (Fig. 2).

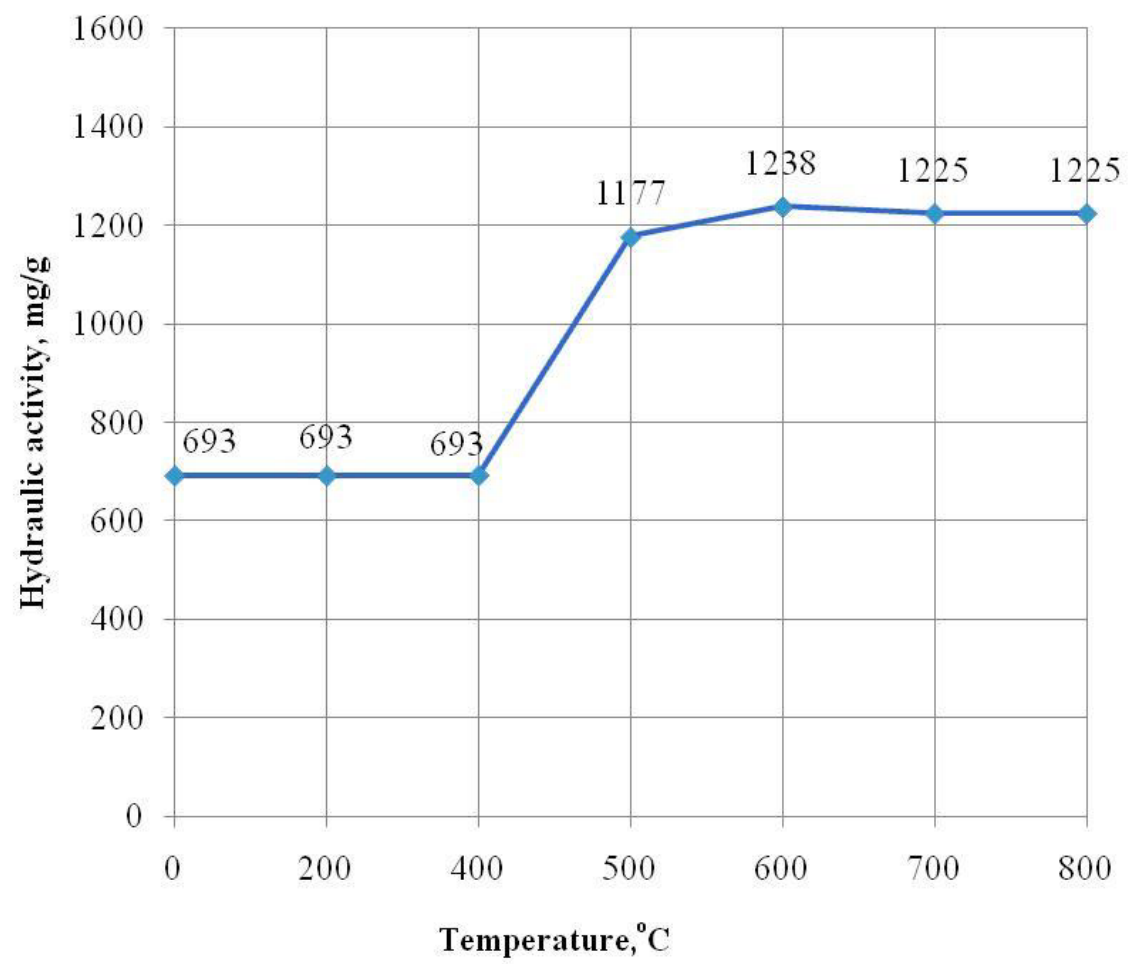

Fig. 1. Effect of firing temperature of kaolin on its hydraulic activity 


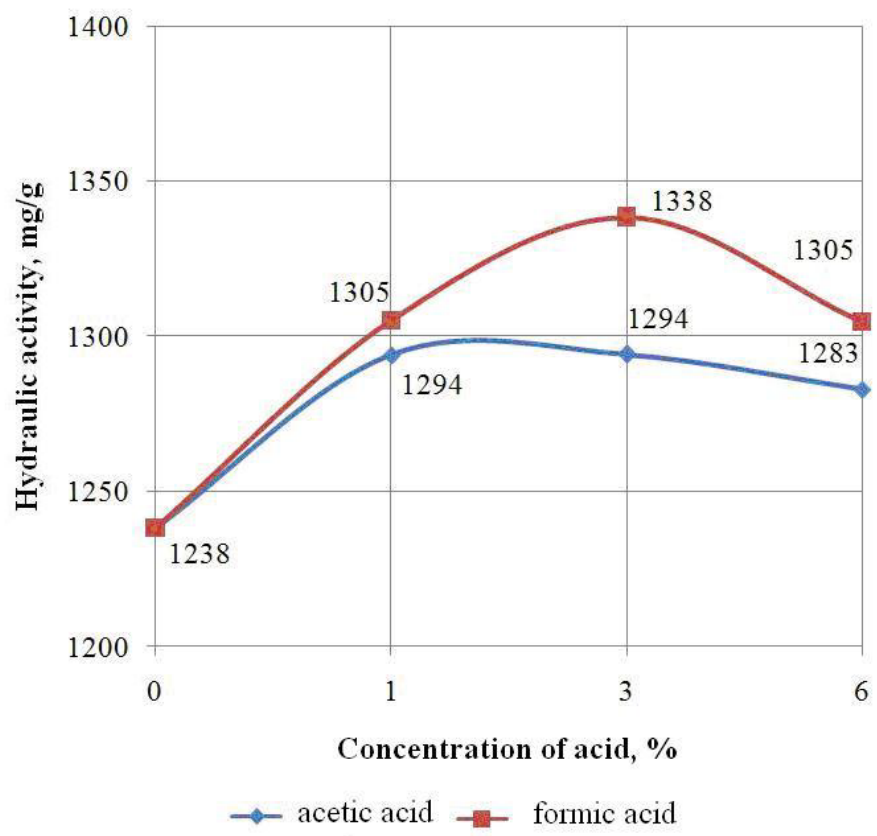

Fig. 2. Effect of acid activation on the hydraulic activity of metakaolin

\section{Result section}

Features on the effect of thermal and acid treatment of kaolin to change its phase composition were researched by IR spectroscopy. Researches metakaolin activated with 3\% solution formic acid (hereinafter referred to metakaolin-A) showed that in the range of wave numbers $3600-2900 \mathrm{~cm}^{-1}$, corresponding to the stretching vibrations of associated $\mathrm{OH}$ groups, and in the 1651-1644 $\mathrm{cm}^{-1}$, a sharp increase intensity of the bands. On the other hand, the relative intensity of the peaks in the frequency ranges $913-912$ and $1032-1029 \mathrm{~cm}^{-}$ 1 , responsible for the perturbation of oxygen-containing groups $\mathrm{Si}-\mathrm{O}$ and the bond in the octahedral layers of $\mathrm{Al}_{3}+\mathrm{O}_{2}$-and $\mathrm{OH}$-, decreases in the 1.6-2.3 times. Of particular interest is the appearance in the IR spectra of metakaolin-A peak in the region $2146-2144 \mathrm{~cm}^{-1}$, which is quite possibly related to education in the communication system $\mathrm{Si}-\mathrm{H}$. Characteristically, with increasing concentration of formic acid in the system with 1 to 3 wt.\% Intensity of this absorption band is doubled, which is probably due to the partial destruction of the aluminosilicate under the action of formic acid. Presumably, in the formation of the solvation shell on the surface of the solid phase increases significantly the number of bound $\mathrm{OH}$ groups, as well as the possible formation of $\mathrm{Si}-\mathrm{H}$-bonds.

So, treatment of metakaolin formic acid can increase the number of associated $\mathrm{OH}$ groups. And probably, can lead to the formation of Si-H-connection.

In the next step of research carried out optimization of the federal program of increased longevity on the basis of the modified mixed binder, through a three-factor second-order plan. The initial independent variables are defined by factors such as content: PCA $\left(\mathrm{X}_{1}\right)$, AMA - metakaolin-A $\left(\mathrm{x}_{2}\right)$, OSC $\left(\mathrm{X}_{3}\right) \mathrm{in} \%$ by weight of cement. As the response of selected flexural strength of FCB (R), water absorption (W) and frost resistance (F).

Produced by processing of the results of mathematical planning has provided the following mathematical relationship:

$$
\mathrm{R}=-43.135+326.4 \mathrm{X}_{1}+3.13 \mathrm{X}_{2}+162.53 \mathrm{X}_{3}+0.35 \mathrm{X}_{1} \mathrm{X}_{2}-2252.9 \mathrm{X}_{1}^{2}-0.053 \mathrm{X}_{2}^{2}-550.86 \mathrm{X}_{3}^{2} ;
$$




$$
\begin{aligned}
& \mathrm{W}=37.44-171.98 \mathrm{X}_{1}-1.82 \mathrm{X}_{2}-60.73 \mathrm{X}_{3}+0.095 \mathrm{X}_{1} \mathrm{X}_{2}-28.57 \mathrm{X}_{1} \mathrm{X}_{3}-0.0476 \mathrm{X}_{2} \mathrm{X}_{3}+1180.21 \mathrm{X}_{1}^{2}+ \\
& +0.0369 \mathrm{X}_{2}^{2}+174.1 \mathrm{X}_{3}^{2} ; \\
& \quad \mathrm{F}=-1757.5+13485.9 \mathrm{X}_{1}+97.58 \mathrm{X}_{2}+3476.64 \mathrm{X}_{3}-91506 \mathrm{X}_{1}^{2}-1.952 \mathrm{X}_{2}^{2}-9436.4 \mathrm{X}_{3}^{2} ;
\end{aligned}
$$

To determine the adequacy of the regression equations obtained, assessed their statistical significance with the tabulated value (Fisher test). In Fig. 3-5 shows a graphical interpretation of the results of processing of mathematical models. As follows from the regression equation (1) and the data shown in Fig. 3, with increased costs AMA and PAA in the fiber-cement mixtures an increase in the strength of the FCB. Joint increasing doses of PCA with AMA, and AMA with OSC leads to a gradual increase in strength, and then to reduce it. Decrease in strength FCB with increasing doses of PCA and OSC, apparently due to a blocking action on the particles of Portland cement additive molecules, which is especially clearly manifested in their joint introduction.

Water absorption (mathematical dependence 2 and Fig. 4) FCB decreases with increasing dosage of OSC and increases with increasing doses of co-PCA and AMA.

The increase in frost resistance, as the mathematical dependence (3) and Fig. 5, occurs at higher dosages of AMA, as well as the combined action of increased additives AMA and OSC. From Fig. 3 shows that the optimum content of modifying agents markedly affects the strength of the FCB. So, on the basis of mathematical experiment planning the optimal dosage of the active mineral and chemical additives in the fiber-cement mixtures: PCA $0.075 \%$, AMA $-25 \%$, OSC $-0.15 \%$ by weight of cement. Further research were carried out taking into account the optimal content of modifying additives in the fiber-cement mixture.

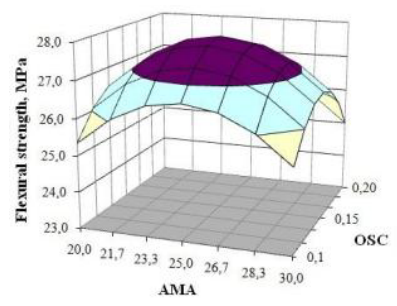

$\mathrm{X} 1$ - const

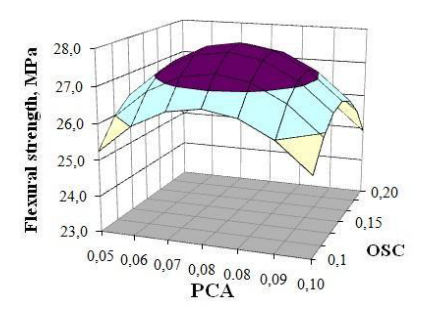

$\mathrm{X} 2$ - const

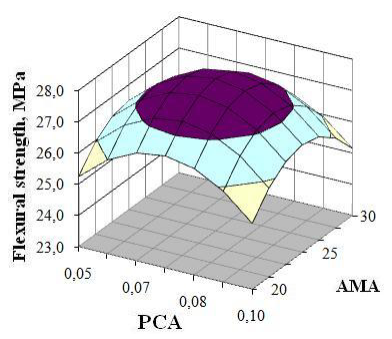

$\mathrm{X} 3$ - const

Fig. 3. Effect of the form and content of the modifying additives on the flexural strength of FCB.

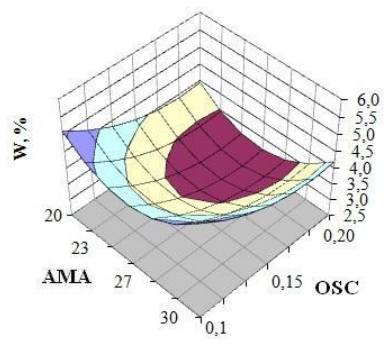

$\mathrm{X} 1$ - const

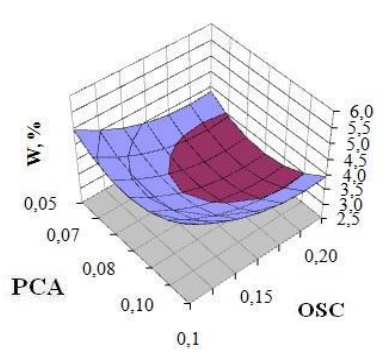

$\mathrm{X} 2$ - const

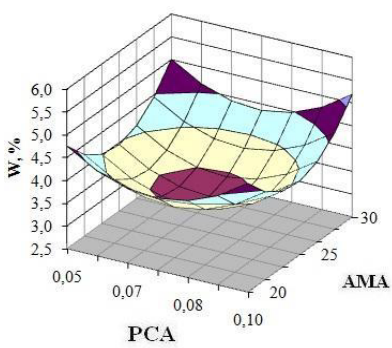

$\mathrm{X} 3$ - const

Fig. 4. Effect of the form and content of the modifying additives on the water absorption of FCB. 


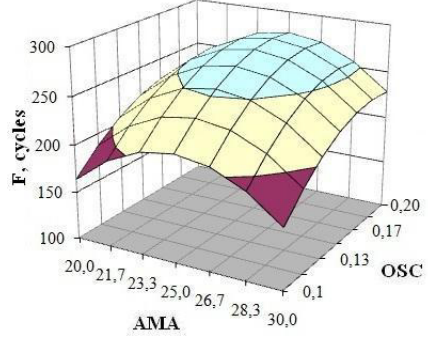

$\mathrm{X} 1$ - const

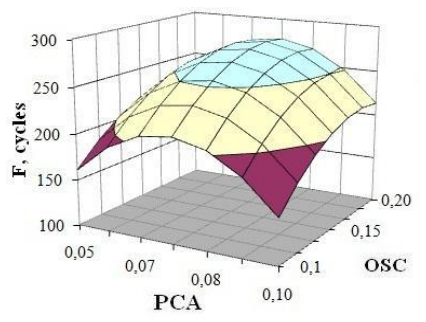

$\mathrm{X} 2$ - const

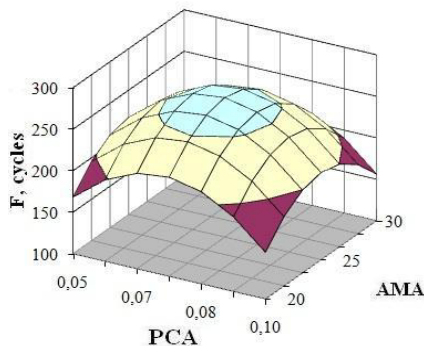

$\mathrm{X} 3$ - const

Fig. 5. Effect of the form and content of the modifying additives on the hardiness of FCB.

On the basis of mathematical experiment planning determine the optimum content of the mixed components of the modified binder for FCB increased durability.

Results of the study phase of fiber-cement matrix based on modified mixed binder showed that in general there is a substantial increase in the number of hydro $\mathrm{C}_{2} \mathrm{SH}(\mathrm{C})$ with an interplanar distance of $2.77 \AA$, lowly basic hydro-type calcium CSH (A) (2.74 $\AA$ ) and tobermorit $(2.97 \AA)$ and lower peak values of $\mathrm{Ca}(\mathrm{OH})_{2}$ and the highly basic types of hydro $\mathrm{C}_{2} \mathrm{SH}_{2}(2.18 \AA)$. Reducing the peak of calcium hydroxide due to its binding to the AMA lowly basic hydrosilicates type calcium $\mathrm{CSH}$.

Research samples of fiber-cement matrix with using differential thermal analysis showed that samples of fiber-cement matrix on the basis of the mixed modified binder is deeper hydration of the silicate phase, as evidenced by an increase in end o effect at $160-170^{\circ} \mathrm{C}$.

IR spectroscopy of cement confirms the results RPA and DTA. Samples FCB of increased durability were tested for shrinkage deformation / swelling resistance of the air and thermal conductivity. Obtained FCB with the following specific characteristics: flexural strength $-27.5 \mathrm{MPa}$, thermal conductivity $-0.22 \mathrm{~W} / \mathrm{m}^{\circ} \mathrm{C}$, shrinkage $-0.2 \mathrm{~mm} / \mathrm{m}$, frost - 250 cycles, resistance of the air - 300 cycles, impact strength $2.5 \mathrm{~kJ} / \mathrm{m}^{2}$.

\section{Conclusions}

1. It has been established that the increase of hydraulic activity kaolin 693 to $1338 \mathrm{mg} /$ $\mathrm{g}$ ensured by thermochemical activation consisting in the preliminary heat treatment at a temperature of $600^{\circ} \mathrm{C}$ and the subsequent activation of the acid in a solution of formic acid.

2. On the basis of mathematical planning of the experiment, the optimal dosage of modifying additives composed fiber cement mixture enhanced durability: PAA $-0.075 \%$, AMA - $25 \%$, OSC $-0.15 \%$ by weight of cement.

3. Shown that the increase physical and mechanical properties and durability of fiber cement matrix due to the formation of optimal microstructure of cement stone, contain high amounts of calcium hydro, mainly lowly basic type.

\section{References}

1. R.Kh. Mukhametrakhimov, A.R. Galautdinov, A.N. Dikina, Izvestiya KGASU, 2, 194200 (2016)

2. A.R. Galautdinov, R.Kh. Mukhametrakhimov, Izvestiya KGASU, 4, 333-343 (2016) 
3. R.Kh. Mukhametrakhimov, V.S. Izotov, Izvestija vysshih uchebnyh zavedenij. Stroitel'stvo, 9, 101-107 (2012)

4. V.S. Izotov, R.Kh. Mukhametrakhimov, L.S. Sabitov, Stroitel'nye Materialy, 5, 20-21 (2011)

5. R.Kh. Mukhametrakhimov, V.S. Izotov, Izvestiya KGASU, 2, 213-217 (2011)

6. N.M. Krasinikova, N.M. Morozov, I.V. Borovskikh, V.G. Khozin, Magazine of Civil Engineering, 51, 46 (2014)

7. V.S. Izotov, R.Kh. Mukhametrakhimov, A.R. Galautdinov, Stroitel'nye Materialy, 725, 20 (2015)

8. R.Kh. Mukhametrakhimov, V.S. Izotov, Izvestiya KGASU, 4, 254-259 (2011)

9. R.Kh. Mukhametrakhimov, V.S. Izotov, Izvestiya KGASU, 2, 250-254 (2010)

10. Patent RF 2486150, Declared 18.01.12, Published 27.06.13, Bulletin № 18

11. R.R. Rjazapov, R.Kh. Muhametrahimov, V.S. Izotov, Izvestiya KGASU, 3, 145-149 (2011)

12. R.Kh. Mukhametrakhimov, V.S. Izotov, Stroitelnye materialy, 710, 116 (2014)

13. V.S. Izotov, R.Kh. Mukhametrakhimov, A.R. Galautdinov, Stroitel'nye Materialy, 740, 70 (2016)

14. Patent RF 2483047, Declared 11.11.11, Published 27.05.13, Bulletin № 15

15. Patent RF 2500633, Declared 04.05.12, Published 12.10.13, Bulletin № 34 